Tohoku J. Exper. Med., 1960, 72, 338-347

\title{
Studies on Experimental Influenza in Mice
}

\author{
IV. Growth Gharacteristics of the PR8 Virus in mouse \\ Tissues Explanted in Vitro
}

By

\author{
Morio Homma, Hajime Kudo and Nakao Ishida \\ Department of Bacteriology, School of Medicine Tohoku \\ University, Sendai; Divector. Prof. N. I shida
}

(Received for publication, May 16, 1960)

Growth characteristics of the PR8 virus in various organs of mice when the inoculum was given from three different routes have been already described ${ }^{11}$. Distribution of the inoculum virus labeled with $\mathrm{P}^{32}$ in these organs just after the introduction into the mice again from three different routes has been also described by pursuing the $\mathbf{P}$ count derived from the inoculum virus ${ }^{2}$. Taken together, the organs which allow the detectable virus growth as far as they are in vivo situation have been found to be lung, liver, spleen and kidney.

Growth of an influenza virus in organs other than lung was thought to be a matter of interest. Though the result described in the first paper ${ }^{11}$ indicated. the unusual growth characterisitics of the virus in the organs like liver, spleen and kidney, obtained evidence suggested at least the possible distribution of this virus through the body even after intranasal infection. This assumption. has been further confirmed by detecting the radioactivity of blood, obtained from mice infected intranasally with $\mathrm{P}^{32}$ labeled virus. ${ }^{2)}$ Thus the distribution of the virus via blood stream is considered to be the case as far as experimental infection in mice is concerned. The fact described above may give an idea to consider murine influenza not as respiratory disease but rather as general systemic one. If this is so, encephalitic or cardiac symptoms found with human influenza cases ${ }^{3)}$ backed up with the evidence of detecting virus in these organs ${ }^{4}$ on autopsy, will be quite conceivable because of the real distribution of the agent. Thus the pathogenesis of influenza infections should be reconsidered on the basis of these findings.

Having these considerations in one hand and also in an effort to find out suitable cell culture system which will allow us the detection of cytopathic effect of this virus on the other, growth of the virus in various mouse tissues has been tested in vitro.

To this end, three types of tissue cultures, i.e. Maitland, Zinsser's agar slant

本間守男, 工藤 笔, 石田名香蜼 
and roller tube cultures were prepared. The order described above was arranged in a fashion from a tissue culture without any cell growth to a tissue culture with full growth.

Facts have been presented that roller tube culture is most suitable at least in detecting the growth of virus in lung, liver and kidney tissues but not in spleen. However, any cytopathic changes have not been accompanied with the virus growth. On Zinsser's agar slant, accumulation of the virus was proved only with lung tissues.

\section{MATERIALS and METHODS}

Virus The PR8 strain of type A influenza virus was used. It has undergone seven passages in ferrets, 593 in mice and 170 in eggs. During these experiments, virus from 170 th to 174 th egg passage was used. Stock virus was obtained as harvested allantoic fluid of eggs after incubation at $37^{\circ} \mathrm{C}$ for $48 \mathrm{hrs}$, which had been infected with $10^{-4}$ dilution of the inoculum. Such fluid contained $10^{9} 8$ $50 \%$ egg infectious dosis $\left(\mathrm{EID}_{50}\right.$ ) and $10^{3.7}$ hemagglutinin (HA) per milliliter.

Assays The number of infectious particles was calculated by usual egg infectious dosis. Hemagglutinin titrations were made by Salk's pattern method. All assay specimens for hemagglutinin titration were pretreated with cholera filtrate by our standard procedure to remove non-specific inhibitors ${ }^{5}$.

Tissue cultures Three types of cultures were examined in order to prove the specificity of each organs in allowing the growth of this virus. The first one is a classic Maitland type culture. Here 15-day-old chicken chorioallantoic membrane was served as the positive control and the virus released into the fluid was examined. Second one is the growth on Zinsser's agar slant. The amount of virus accumulated in the tissue fragment incubated on the slant was examined. Here the minced tissues of both chorioallantoic membrane and chick embryo obtained from 15-day-old egg were used as the control. Third type of culture employed was the usual roller tube culture.

Practical procedure in preparing tissue culture cells

1) Maitland type cultures

Brain, lung, liver, kidney, spleen, pancreas and muscle were removed aseptically from adult mice of white dd strain, the mice which had been used throughout this series experiment. After two times washings by changing Hanks' solution, they were cut into small pieces with the aid of scissors and $300 \mathrm{mg}$ amount was distributed in each small test tube. $2 \mathrm{ml}$ amount of Hanks' solution containing inoculum virus (finally $10^{-3}$ dilution of the stock virus) was then added to these tubes. The amount of virus in fluid was examined at 24 and 48 hrs after incubation at $37^{\circ} \mathrm{C}$. Details to perform the experiment have been already 
described elsewhere. ${ }^{\text {" }}$

2) Zinsser's agar slant cultures

Eight $\mathrm{ml}$ amount of Zinsser's agar medium (mixture of $4.5 \%$ purified agar, $2 \times$ Hanks solution and bovine serum in a ratio of $3: 3: 2$ ) was solidified as a slant in test tubes. Firstly, $700 \mathrm{mg}$ of tissue fragment, obtained as described above was infected in petri dishes with $0.3 \mathrm{ml}$ of $10^{-2}$ diluted virus. They were incubated for 30 minutes at room temperature for the infection. Then the fragments were washed carefully with Hanks' solution in petri dishes to remove the inoculum. The tissues thus freed from the inoculum were collected with the aid of spatula and $200 \mathrm{mg}$ amounts of tissues were put on each three slant. The remaining $100 \mathrm{mg}$ was served as testing the inoculum virus titer. These tubes were incubated at $37^{\circ} \mathrm{C}$ and the virus assay was made at a day or 2 days interval as long as 4 or 5 days. In titrating the virus activity, these tissues obtained from 3 tubes were combined and ground in ball and mill to make a $10 \%$ suspension. Centrifuged supernatant at 3,000 rpm for 10 minutes was used for virus assays.

3) Roller tube cultures

Only in this experiment, tissues were obtained from suckling mice of 3-dayold dd strain, because of the reproducible cell growth. Brain, heart, lung, liver, kidney, spleen, pancreas and muscles were resected from mice aseptically and cut into a small piece of average $1 \mathrm{~mm}$ diameter. In each test tube, 6 pieces were fixed by means of plasma clot. 2 tubes were employed for one assay. YLE solution $10.5 \%$ lactalbumin hydrolysate and $0.1 \%$ yeast extract in Earle's solution with $0.45 \%$ glucose), bovine serum and chick embryo extract $(1: 1)$ were mixed up in a ratio of $65: 30: 5$ and $2 \mathrm{ml}$ amount was used as the growing medium in each tube. Though the growth rate was different from tissue to tissue, the best growth was usually obtained after 5 days incubation at $37^{\circ} \mathrm{C}$. For the virus growth experiment, the maintenance solution which was composed of YLE, inactivated horse serum and CEE $(1: 1)$ with a ratio of $85: 10: 5$ was used throughout. Then the inoculum was drawn off and these tissues were washed 3 times with $2 \mathrm{ml}$ amount of Hanks' solution. Then the $2 \mathrm{ml}$ amount of maintenance solution was refed to each and virus assays were made with these fluids.

\section{EXPERIMENTAL}

\section{No detectable growth of the PRS virus in Maitland type culture of various mouse organs}

Practical technics to do this have been already fully described in a section of materials and methods. The results were illustrated by Fig. 1, where the virus titer in a fluid was examined after 24 and 48 hrs. of incubation. Chorioallantoic membrane served as the control gave a good growth of the virus 

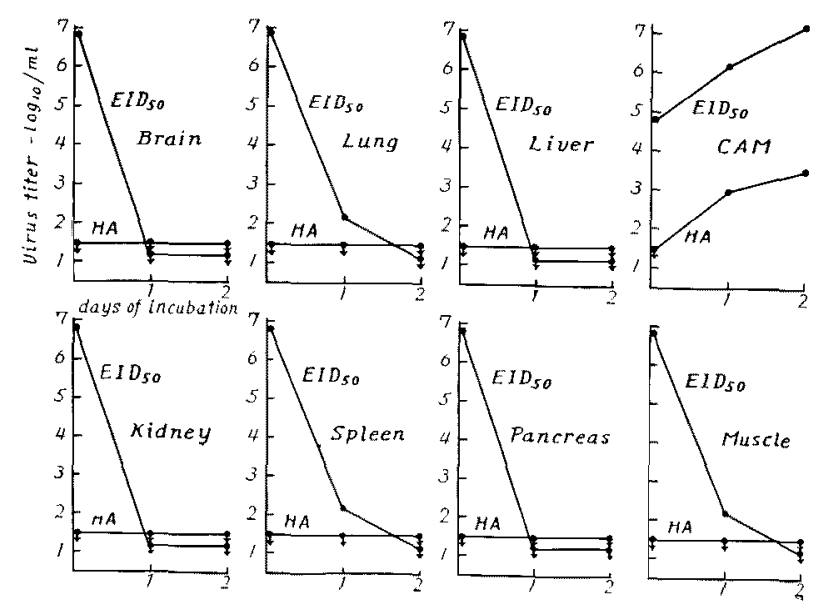

Fig. 1. Growth curves of PR8 virus in Maitland type cultures of various mouse tissues. Chorioallantoic membrane (CAM) was served as the control.
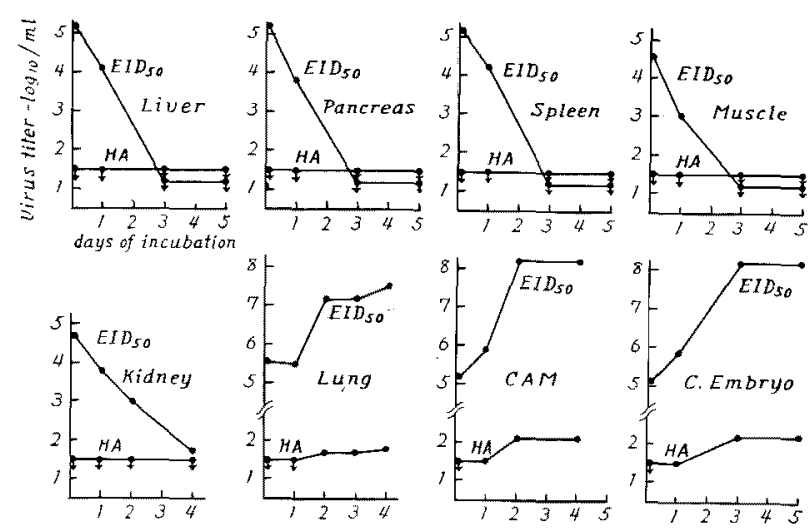

Fig. 2. Growth curves of PR8 virus on Zinsser's agar slant cultures of various mouse tissues. Chorioallantoic membrane (CAM) and chick embryo were served as controls. Amount of virus was examined by titrating both $\mathrm{EID}_{50}$ and $\mathrm{HA}$ with $10 \%$ homogenate of each.

when examined both by means of $\mathrm{EID}_{50}$ and $\mathrm{HA}$. On the other hand, no measurable virus growth with mouse tissues such as brain, lung, liver, kidney, spleen, pancreas and muscle has been noticed. Only with tissues of the lung, spleen and muscle, there was a tendency to maintain the virus titer in a fluid a little better than with other tissues, when infectivity titration of the fluid was conducted with the harvests, obtained at 24 hrs. But the fact was not taken for 
further considerations.

Virus growth in lung tissues on Zinsser's agar slant

In the second place, the accumulation of virus in tissues on Zinsser's agar slant was tested and the results were summarized in Fig. 2. The advantage of this culture when compared to the former Maitland type culture will be in the relative heat resistance of the virus inside the cell or attached to the cell when compared to the free virus. The result illustrated in Fig. 2 shows the growth of virus in lung tissues as well as in tissues derived from chick embryo and chicken chorioallantoic membrane. In this experiment, growth was pursued every day or every two days up to 4th or 5th day after infection, where the growth practically reached to the maximum after 2 or 3 days of incubation. Final growth in lung, however, was_almost one tenth of that obtained in chick embryo or chicken chorioallantoic membrane. In lung tissues, HA was also detectable and I/A

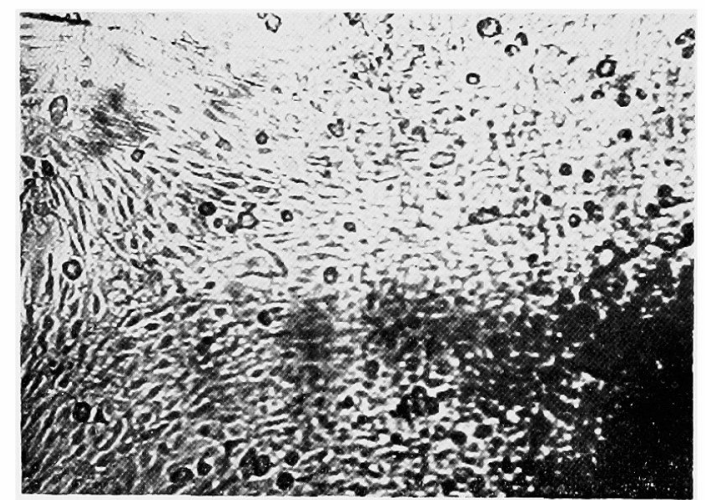

Fig. 3-a. Portıon of a living roller tube culture of mouse lung tissues. $\times 80$.

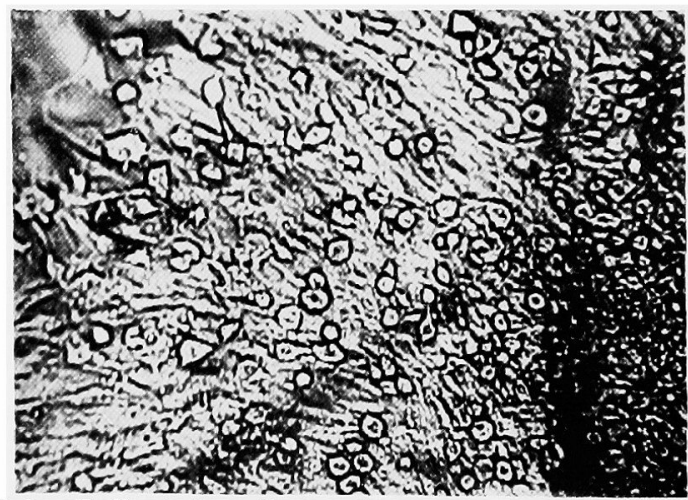

Fig. 3-b. Roller tube culture of mouse spleen tissues. $\times 80$. Note the rounded or rather hexagonal cells extending outward. 


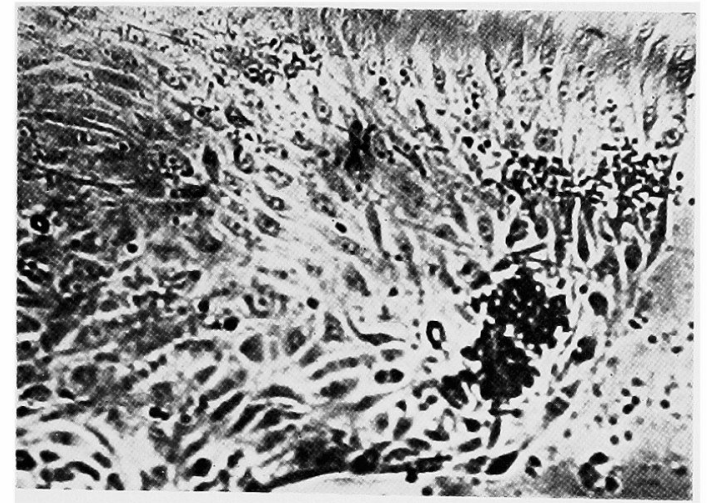

Fig. 3-c. Roller tube culture of mouse kidney tissues.

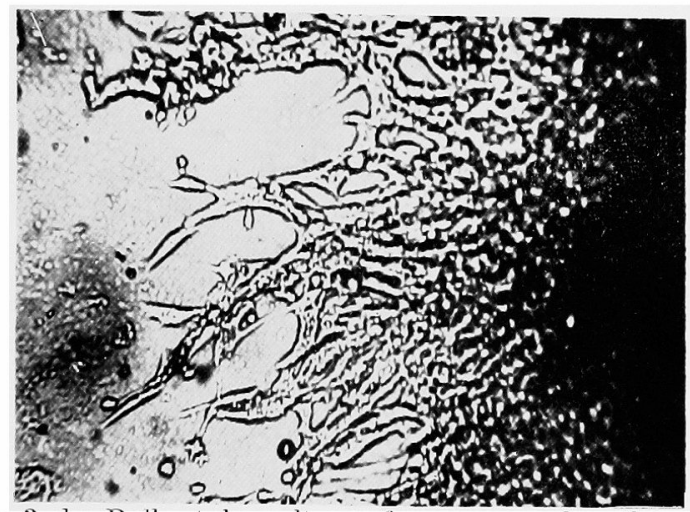

Fig. 3-d. Roller tube culture of mouse muscle cells. : 80 .

$\left(\mathrm{EID}_{50} / \mathrm{HA}\right)$ ratio was calculated as 5.7. Thus nearly complete growth was found in this condition.

Cell growth from various mouse organs in roller tube cultures

Except brain, all of the organs tested for the cell proliferation gave a good result (see Fig. 3).

Cell grown from lung, liver, heart and pancreas explants had predominantly the appearance of fibroblasts, but some other cells which had the appearance of epithelial cell or histiocyte were also detectable. In Fig. 3-a, maximum growth obtained with lung tissues was illustrated. Among the tissues tested so far, spleen gave the best growth. However, growth characteristics of the cell derived from spleen were different from the former four. Migration of round cells was first revealed around the explanted tissues. They were different from fibroblasts and some of them were rather hexagonal. Then an overgrowth of fibroblastic cells was followed and as a result the explant itself was digested. By these means, 
almost monolayered fibroblast cultures with some scattered round cells of epithelial character were finally obtained (Fig. 3-b). With kidney, predominant epithelial cell growth occurred with some fibroblastic cell (Fig. 3-c). This feature was not different from that found with the same organ of the other animals. Colonial growth of epithelial cells were usually surrounded with the sheets of fibroblasts. With muscle (Fig. 3-d), only the growth of muscle cells were provable.

Growth of the PR8 virus in roller tube cultures

Tissues other than lung, kidney and liver did not allow the growth of the virus. These results were shown in Fig. 4, where the virus liberated into the liquid phase has been assayed at 48 hrs intervals. Brain tissues without appreciable cell growth was referred to serve as the control indicating the heat inactivation of the virus.
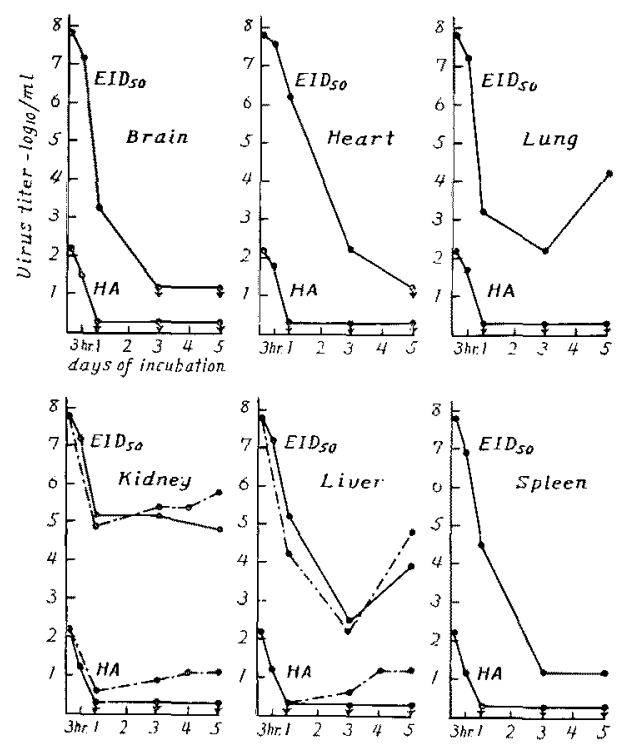

Fig. 4. Growth curves of PR 8 virus in roller tube cultures of various mouse tissues. Differential virus assay was made every 2 days by titrating the $\mathrm{EID}_{50}$ and $\mathrm{HA}$ of culture fluid. Dotted line shows another experimental result, where accumulated titer was examined.

In kidney, growth tendency was not so discernible in such a differential response examination. Obvious eclipse period was not found as can be seen in the figure. However, the titer held relatively high up to the 5th day. Thus another experimental run was carried out where the titer in the fluid accumulated after appropreate incubation period was tested. In the figure, the dotted 


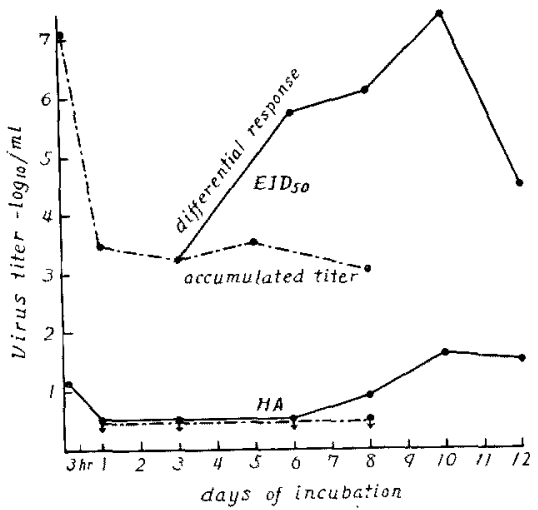

Fig. 5. Growth curves of PR8 virus in roller tube culture of mouse lung tissue. Two different system were adopted for testing virus growth (see text).

line showed the latter result and the growth tendency was now became evident. The shift of hemagglutinin titer was also detectable even if in low level.

In liver and lung, the same type of growth curve was obtained but the rise of infectious titer was first evident after 5 days of incubation. The latent period was thought to be rather longer than usual. Thus the accumulated virus titer was again exmained first with liver (dotted line in Fig. 4). In this case, the result was almost identical with that of differential response experiment. Thus the idea of slow maturation in these situation was hold. To approve this idea, again differential response experiment was repeated with lung tissues but for a longer period. This result has been illustrated by Fig. 5. In the figure, dotted line shows the accumulation curve where the significant rise of infectious titer is not obtainable. Contrary to this result, if differential response experiment was made for a longer period, the release of virus from the cell was shown to be fairly high but relatively slow. Exchange of medium seems to be favourable for virus liberation, at least in this condition.

With cultures derived from heart and spleen, no appreciable growth was recognized as shown in Fig. 4. This was also the case with cultures obtained from pancreas and muscle, thus the results were omitted.

Throughout the experiment, no cytopathic changes have been recognized with these tissues, as far as when they are examined microscopically without any staining. The fact together with the release of large amount of virus into the medium only when the medium was changed often as has been the case with lung tissues, may suggest the possibility of latent type infection but this was left for further studies. 


\section{DISCUSSIONS}

It has been observed that a tissue entirely resistant to a viral infection in vivo may become highly sensitive to the same infection after explantation in vitro. This phenomenon is well illustrated by the behavior of the kidney of the monkey in which no multiplication of poliovirus occurs when the agent is inoculated directly in the organ in vivo ${ }^{7}$. However, monkey kidney cell supports a rapid multiplication of the same virus when separated from the organism and maintained in tissue culture. In turn, if the growth of virus was detectable in some organs in vivo, the fact may indicate that there may be a cell which will allow the growth of virus when they were maintained in vitro under proper condition. Having these considerations in mind, tissues derived from various mice organs were examined whether some of them which had been shown to allow the virus growth in vivo may support the growth of the same virus in vitro or not.

First of all, the lung tissue has been characterized by the fact that the reasonable amount of virus accumulation was shown even on Zinsser's agar slant. Moreover, the virus found in this condition was fairly complete in testing the I/A ratio.

Among the three types of cultures, here employed, roller tube culture was most suitable in detecting the growth of PR8 virus. Though the exact number of cells participated to the real virus multiplication was not determined because of the nature of cultures, cells derived from kidney and liver explants were also proved to allow the growth of virus in addition to that from lung. This fact should be taken into account in considering the pathogenesis of influenza infections in vivo, though does not approve the idea that the virus growth in these organs of mice is really the case. ${ }^{11}$

Attempts to propagate the virus in the culture derived from spleen has been failed in spite of the excellent growth of the cell mainly of fiborblastic appearance. Many explanations, such as the selected growth of some resistant cells in vitro, or influence of immune mechanisms or so on will be applicable but the fact was not pursued so far.

Unfortunately, cytopathic effect of the virus was not detectable in this experiment. The fact is concordant to many observations made on related subjects. However, in a light of Tyrrell's recent paper ${ }^{8)}$, the fact should be further examined in detail. Particularly the fluorescent antibody techniques will give us an indication in visualizing the kind of cell, really participating to the viral multiplication. This effort is now under progress and this kind of experiment may lead to a new conclusion in analyzing the necrotic effect of influenza virus on bronchial epithel, which has been believed to be the characteristic toxic action of the virus. 


\section{SUMMARY}

The PRS strain of influenza virus was examined on the growth ability in three types of tissue cultures derived from various mice organs.

In Maitland type culture, the release of virus into a medium was not detectable with tissues of brain, lung, liver, kidney, spleen, pancreas and muscle. Whereas the excellent proliferation was proved with chicken chorioallantoic membrane examined under the same condition. When these tissues were placed on Zinsser's agar slant, viral multiplication was found only with lung tissues. However, the amount of virus here found was almost one tenth of that obtained with chick embryo and chicken chorioallantoic membrane used as the control in the same way.

Roller tube cultures were carried out with explants derived from various mouse organs obtained from 3-day-old mice. Reasonable growth of the cell eligible for viral growth study was obtained with lung, liver, kidney, spleen, pancreas, heart and muscle. When they are infected in vitro, growth of virus was found in tissues of lung, liver and kidney in concordant with the result obtained in animal experiment. However, in tissues of spleen any growth signs were not obtained. Daily change of the medium was favourable in detecting the release of virus from the lung tissue into a medium.

\section{References}

1) Ishida, N., Mizuno, H. \& Chiba, A., Tohoku J. Exper. Med., 1959, 71, 137.

2) Ishida, N., Kosaka, Y. \& Sasaki, Y., Tohoku J. Exper. Med., 1959, 71, 151.

3) Silber, E.N., Ann. Int. Med., 1958, 48, 228.

4) Kaji, M., Oseasohn, R., Jordan, W.S. \& Dingle, J.H., Proc. Soc. Exp. Biol. \& Med., $1959,100,272$.

5) Sasaki, H., Virus (Jap.), 1959, 9, 404.

6) Ishida, N., Ansai, O. \& Horigome, E., Virus ( Jap.), 1958, 8, 240.

7) Kaplan, A.S., Virology, 1955, 1, 377.

8) Heath, R.B. \& Tyrrell, D.A.J., Arch. ges. Virusforshg., 1959, 8, 577. 